\title{
Informed consent: what does it mean?
}

\author{
Hon Mr Justice M D Kirby Chairman of the Law Reform Commission of Australia
}

\section{Author's abstract}

The editorial in the September 1982 issue of this journal and many articles before and since have addressed the problem of informed consent. Is it possible? Is it a useful concept? Is there anything new to be said about it? In this article the basic rationale of the rule (patient autonomy) is explained and the extent of the rule explored. Various exceptions have been offered by the law and an attempt is made to catalogue the chief of these. A number of specially vulnerable groups are then identified, the most important, and vexed, being children. How can informed consent be secured in the case of young patients? Finally, a few problems are mentioned in an attempt to get this subject back to reality. The appeal to the principle primum non nocere may be medical paternalism in disguise. Informed consent is the competing principle that reminds us of the primacy of human autonomy. A pointer is given to the future: even the use of sound recordings to explain medical procedures and to activate informed consent so that it may become a reality and not just a lawyer's myth, should be considered.

The article is based on a paper delivered at the Royal Prince Alfred Hospital, Sydney to the Association of University Clinical Professors of Australia.

\section{Definitions}

The principle of informed consent requires that health professionals, before any diagnostic or therapeutic procedure is carried out which may have any reasonable possibility of harm to the patient, explain to the patient what is involved in order to secure the understanding consent of the patient to proceed (1). An informed consent is that consent which is obtained after the patient has been adequately instructed about the ratio of risk and benefit involved in the procedure as compared to alternative procedures or no treatment at all (2). There has been relatively little discussion of the topic in the courts of Britain or Australia (3). But in the

\section{Key words}

Informed consent; legal informed consent; patient autonomy; medical paternalism; detailed video and sound recordings for patient consent; basic rationale.
United States, about half of the States already have statutes which seek to specify the legal requirements of informed consent, often to protect the medical profession against decisions of the courts thought to be too onerous.

In the case of Williams v Menehan (4) the Supreme Court of Kansas stated the principle well:

It is the duty of the doctor to make a reasonable disclosure to his patient of the nature and probable consequences of the suggested or recommended treatment and to make a knowledgeable disclosure of the dangers within his knowledge which are incident or possible in the treatment he proposes to administer.

In that case, a patient had a bilateral mastectomy for cancer of the breast and several burns followed subsequent radiation therapy. The court held that if the patient knew of the risk, no disclosure would be necessary and that the doctor might not have to discuss risks if to do so would harm the patient. I shall come back to these exceptions.

Various sources are quoted for the doctrine of informed consent, including Biblical passages and philosophical writings. The Nuremberg Code adopted in 1947, and the World Medical Association's Declaration of Helsinki, now provide international statements of the duties of doctors, particularly in experimental or innovative treatment where special difficulties can arise. The Declaration of Helsinki states:

Clinical research on a human being cannot be undertaken without his free consent after he has been fully informed; if he is legally incompetent, the consent of the legal guardian should be procured (5).

The same Declaration also puts it this way:

If at all possible, consistent with the patient's psychology, the doctor should obtain the patient's freely given consent after the patient has been given a full explanation. . . Consent should, as a rule, be obtained in writing. However, the responsibility for clinical research always remains with the research worker; it never falls on the subject even after consent is obtained (6). 
The efforts at definition at Nuremberg, Helsinki and in the enormous bulk of recent medical and legal literature on this topic, have been criticised as vague, too general and unhelpful to the health care worker on the spot. It seems to be agreed that it is hard to define the expression 'informed consent' in a way that will accommodate all of the ramifications of interpersonal relationship that can arise in the dependent environment of health care (6). Various formulations which are offered by courts or legislators are themselves assailed as simply playing with words. Mr Justice Frankfurter, in the United States Supreme Court, said of an expression similar to 'informed consent' that it was 'an excellent illustration of the extent to which uncritical use of words bedevils the law'. He claimed that:

A phrase begins life as a literary expression; its felicity leads to its lazy repetition; and repetition soon establishes it as a legal formula, undiscriminatingly used to express different and sometimes contradictory ideas (7).

Playing with the words 'informed consent' will not cut much ice with health care professionals working in the often stressful, emergency and highly complex and technical world of modern medicine.

\section{Principle and rationale}

This having been said, it is important for us to go to the heart of the problem to understand what it is that is behind the notion of 'informed consent'. What is it that theologians, moral philosophers and lawyers are getting at in talking about this patient consent?

Originally, the notion was explained in the legal casebooks as being based upon the need for the patient to be able to 'take courage' as he, or she, faced up to the dire predicament of pre-anaesthetic medicine. In 1767 it was put thus:

It is reasonable that a patient should be told what is about to be done to him, that he may take courage and put himself in such a situation as to enable him to undergo the operation (8).

Although medicine has come a long way since 1767 , the need for patients to take courage and to prepare themselves for medical treatment is still a reality today.

Nowadays, a broader concept is taken as the rationale for informed consent. It is the right of selfdetermination. A recurrent feature of our civilisation is said to be respect for the autonomy of the individual human being, 'with inherent dignity and value' (9). Each of us is said ultimately (with rare exceptions) to have the right to control our lives and actions by our own choices, at least to the greatest extent compatible with the rights of others (9). The fundamental principle underlying consent is said to be a right of selfdetermination: the principle, or value choice, of autonomy of the person (10). This fairly general notion is articulated in different ways. It is said to be based on inherent natural rights. It is said to be grounded in a political notion of the importance of the individual. It is claimed to be based upon the right of the patient to 'chart his own destiny' with such information as the health care professional can provide in order that the patient can do so intelligently and with dignity (11). The principle is not just a legal rule devised by one profession to harass another. It is an ethical principle which is simply reflected in legal rules because our law has been developed by judges sensitive to the practical application of generally held community ethical principles.

A modern interpretation of the principle of informed consent is offered in these terms:

The legal doctrine of informed consent clearly rests upon ethical principles of autonomy and selfdetermination. .. The ethical need for informed consent in medical practice was a salutory reminder to doctors that their patients were people and not cases and that the patient/doctor relationship needed to be open and honest in recognition of and respect for each patient's autonomy (12).

\section{Extent of the rule}

The rule comes into the law and is supported by causes of action which have been developed to provide remedies for people who feel themselves wronged. These remedies lie in the criminal and civil law but I shall concentrate on the civil remedies. The most usual way in which the notion is explained is by reference to the law of trespass to the person and battery. The whole basis upon which a health care professional is exempted from the civil (and criminal) wrongs of intentionally and injuriously touching the person of a patient is the latter's consent. If that consent is absent or if it is not truly present, then, touching being proved, the lack of consent gives rise to the legal cause of action. All the necessary elements are present if consent is absent.

An alternative way in which the cause of action can be framed lies in negligence. A health care worker will not incur liability in negligence unless it be established that he owed a legal duty of care to the patient, that he was in breach of that duty and that the patient suffered damage in consequence. In cases framed in negligence, the issues revolve around whether the amount of information a doctor has disclosed to the patient was adequate to comply with the established standard of care that is expected of him. A medical worker will not be liable in negligence simply because he has failed to comply with the required standard of care. There must be proof of damage. In these cases, the patient must establish that if he had received the information that should have been given to him, he would not have given consent to the procedure that led to the damage (13). These are the alternative ways in which the claim can be mounted in law. Usually, of course, claims arise only when something has gone wrong, resulting either in injury to or death of the patient. Indeed, usually, unless something seriously wrong has occurred, the costs, 
delays and other inconveniences of litigation dissuade patients and their families from suing, certainly in Australia or Britain, where cost rules are different from those of the United States.

The obligation of securing patient consent therefore arises both to meet the appropriate standards of care (negligence) and to avoid liability in battery (trespass to the person). The question remains as to what the health care professional must tell the patient. Various formulations have been offered. The Law Reform Commission of Canada in 1979 suggested in a study paper the following as a 'desirable approach':

1) All material or relevant facts must be disclosed as well as other factors related to the treatment which could influence the patient's decision to participate, that is the disclosure must be complete, accurate and not too complicated;

2) The test of materiality of information should be objective vis-a-vis a 'reasonable patient', with the proviso that this test becomes subjective to the extent that the physician knew, or ought to have known, that additional information which would not have been relevant to the 'reasonable patient' was in fact material to this particular patient . . . ;

3) The test of required comprehension of the disclosure should be 'apparent subjective', that is the doctor must take reasonable steps in relation to the particular patient to ensure that he has understood and that objectively, or apparently, he did;

4) Care should be taken that the informing process is not coercive; and possibly in some circumstances an estimation should be made by a 'disinterested' outside party in this respect . . .;

5) In non-therapeutic experimentation there can be no mitigation of these standards and no waiver of the right to be informed is allowed; and

6) In the therapeutic situation waiver, 'therapeutic privilege', and a duty not to inform may all apply depending on the circumstances but generally there should be a presumption that they are inapplicable, with the burden of proof to the contrary on the person alleging this and with the rebuttal of the presumption only being upheld when the circumstances clearly indicate it (14).

Some of these statements may be arguable. Some may state the desirable rather than the current legal position, at least in Australia. Other formulations have suggested that the duty of the health care professional is to describe the proposed treatment, to indicate the alternatives, to outline the inherent risks of death or serious bodily injury, to refer to any problems of recuperation that may be anticipated and to give any additional information which would normally be disclosed in the circumstances (15). The duty is clearly not a 'once-and-for-all' duty. It is a continuing one, lasting during the whole course of the medical treatment, so that if circumstances or the pattern of treatment change, fresh and continuing consent should be obtained (16).

\section{Exceptions}

Various exceptions have been suggested to the obligations that I have just outlined. They include:

\section{EMERGENCY}

The case of the genuine emergency, where the health care must be given immediately. But even in these circumstances, the law implies the scope of authority from the patient. Where a patient is rendered unconscious in an accident or has a heart attack or is otherwise incapable of consenting and no other person is available capable of giving consent on his behalf, the medical practitioner, facing the predicament of the need of immediate medical care, will be protected by the law if his performance of medical procedures is reasonable in the circumstances.

PATIENT KNOWLEDGE

It has been suggested that it is not necessary to secure specific consent where the patient has full knowledge, either by reason of previous discussions, his own expertise or otherwise of the procedure, its risks and possibilities. Certainly, the medical practitioner is not under an obligation to describe in detail all of the remotely possible consequences of treatment (2).

ONLY ONE COURSE

It has also been suggested that, akin to the emergency case, there is no obligation to secure informed consent where there is only one possible course open to the medical practitioner. However, I think this is a dubious exception as, even in such a case, the patient might want to secure an alternative opinion, consultation with his family or the ultimate right to refuse treatment: a right that has lately been upheld, even in terminal cases, before United States courts.

NO CHANCE OF HARM

It has been suggested that another exception arises where there is no danger in the proposed procedure or where the danger is so remote because the procedure is so simple, commonly appreciated or known to the particular patient that it would be tiresome and pointless to explain the procedure to the patient (17). Again, I question this exception. If there is no chance of harm, it is a simple matter to say this to the patient, leaving the ultimate decision to the patient himself.

NOT AGAINST WISHES

Sometimes a patient does not want to be informed. This situation may arise either because of the resignation of the patient to any treatment the doctor may think necessary, the fear that full revelation of the risks will be too distressing or because of the impatience of the patient with what is seen to be defensive medical practice. If the patient does not wish to be informed and makes this quite clear, a doctor need not force information upon the patient. Especially in terminal conditions, kindness and gentleness in dealing with patients remain an essential aspect of medical practice. But so does personal autonomy. It has been said that it is sufficient for the doctor in such a case to take the patient to the brink of revelation: to suggest that it would be well to put one's affairs in order or to propose 
discussion with a member of the family. In cases of this kind, particularly where detailed discussion of the risks is likely to 'alarm the patient' courts have relieved the health care professional from any duty to labour the point. The guiding star of the medical practitioner remains doing what is best for the patient. The health care professional may accordingly modify the extent of his disclosure to a particular patient to avoid causing unnecessary anxiety, apprehension or distress on the part of the patient in the course of treatment (2).

GENERAL TERMS

As is implied above, it is sufficient for the information to be supplied to the patient in general terms. There is no obligation to go over with the patient anything more than 'the inherent implications' of the particular procedure proposed for treatment (18).

\section{PATIENT'S BEST INTERESTS}

Apart from cases of alarm and distress, there may rarely be cases where it is the medical practitioner's judgment that it is contrary to the best interests of the patient to know. In North America this concept has given rise to the so-called doctrine of 'therapeutic privilege' under which, in a particular case, telling the patient some or all of the information required to be given under the general rule would in itself harm him physically or mentally. This is a rare case indeed. It is not sufficient that disclosure would affect the patient's decisionmaking. For the right to make the decision is an important and inherent aspect of the patient's autonomy. Nor is a paternalistic assessment - 'doctor knows best' - appropriate in today's world. However, there may be exceptional cases - they must be narrowly confined and they place a heavy burden upon the medical practitioner to justify them - where no information, no hint, no suggestion is appropriate because of the disproportionate harm it would do the patient. In such cases, at the very least, it would be wise, if not self-protective, for the doctor and the hospital involved to secure discussions with members of the family or close friends and relatives of the patient, so that no suggestion can be made that the medical practitioner has simply substituted, in a serious medical decision, his own assessment of the patient's good for the patient's assessment.

\section{Specially vulnerable groups}

Much of the literature on informed consent deals with the special problems of particularly vulnerable groups from whom it is difficult to secure a full, free, informed and knowing consent. The classes normally referred to include:

- mental incompetents (19)

- prisoners (20)

- terminal patients (19)

- the fetus (19)

- pregnant women (21)

Informed consent in the case of these specially vulnerable groups will not be discussed. The problem of securing consent from young persons is the one that most frequently arises. It is inappropriate for the law to impose an arbitrary temporal age before which parents only can consent and after which the child has full autonomy and control over medical treatment. The Australian Law Reform Commission itself ran into some of these problems when it proposed such an arbitrary approach in its discussion paper which dealt with access by children to health and like records (22). This proposal is now being reconsidered. The inability of a child, or for that matter a mentally ill or retarded person, to give a truly voluntary and properly informed consent, at least in the case of a child during early childhood, creates the problem. So far as children are concerned, there is always someone in loco parentis - the natural parent, the adoptive parent, a guardian, legal guardian or the Minister. Courts will review the judgment of a legal guardian concerning the child's best interests in medical treatment. The Supreme Court of New South Wales recently ordered that a 15-year-old State ward in a home for emotionally disturbed children could undergo an abortion contrary to the earlier decision of her legal guardian, the Minister for Youth and Community Services. The court in that case made a judgment on medical evidence as to the child's best interests, augmenting in that case the wishes of the child, her natural mother and medical advisers. As the child grows older, whether still in the legal custody of parents or others, the sufficiency of a purely proxy consent may be called into question both under common law and by statute. Even more acute problems can arise where non-therapeutic experimentation on young people is proposed. Campbell has suggested that in such cases permission from the parents coupled with proper external assurances of the integrity of the investigator are the child's best protection. Guidelines for non-therapeutic research are suggested to balance the protection of the young patient on the one hand and the need for investigators to have a degree of freedom to prosecute worthy research, vital to continued improvements in child care (21).

As the child emerges to an age at which rational decisions can be made, respect for the principle of individual autonomy will require that information be given to the child about treatment and, even more so, about non-therapeutic experiments.

\section{Some problems}

The discussion I have so far offered indicates a number of problem areas in defining the meaning and scope of the obligations to secure informed consent.

In the first place, from a lawyer's point of view, it must be stressed that the cases that come to courts and to lawyers tend to be exceptional. They tend to be serious. They represent only the tip of the iceberg of the problem of consent and informed decision-making by patients in their health care. Furthermore, most of them revolve around factual disputes about what was said or not said. Each tends to depend upon its own 
particular facts and therefore few general principles can be drawn, other than those of the level of generality I have already mentioned (23).

Secondly, it must be frankly recognised that to some extent at least the notion of 'informed consent' is simply an ideal to which daily practice can only aim. Some commentators have suggested that it is an ideal in the nature of a myth. This is said because it is impossible for the health care professional to impart to the patient every facet of his knowledge and expertise involved in the decision. A lifetime or at least many years of experience and judgment may lie behind the decision. This cannot be imparted, in the real world, in the space of a 30-minute consultation. Patients vary enormously both in their interest in and capacity to absorb information about medical procedures. It is the very expertise of the health care professional that brought the patient to him. To this extent consent is that by a less knowledgeable person to one who is more knowledgeable' (2). Research by Cassileth and others about the operation of informed consent in practice reveals why the goals of this ideal are imperfectly realised:

Within one day of signing consent forms for chemotherapy, radiation therapy or surgery, 200 cancer patients completed a test of their recall of the material in the consent explanation and filled out a questionnaire regarding their opinions of its purpose, content and implications. Only 60 per cent understood the purpose and nature of the procedure, and only 55 per cent correctly listed even one major risk or complication. We found that three factors were related to inadequate recall: education, medical status and the care with which patients thought they had read their consent forms before signing. Only $\mathbf{4 0}$ per cent of the patients had read the form 'carefully'. Most believed that consent forms were meant to 'protect the physician's rights' (24).

To some extent the very notion of informed consent implies a sophistication on the part of the patient. At least where the procedures are of any complexity, relatively few patients will approach this sophistication and the law must take this reality into account.

Thirdly, there is the practical issue of how the content of consent is to be assessed. From the point of view of the medical practitioner, he may contend that the best he can do is to accord with normal medical practice, offering the degree of detail and information offered by his colleagues in like cases. However, courts, rejecting a paternalistic approach to the assessment of what has to be told to a patient have made it plain that it is not appropriate to surrender the degree of detail to the sole judgment of the medical profession itself (25). The question of how much information a doctor should disclose concerning a proposed procedure is one on which the courts should not consider themselves bound by evidence of current medical practice and opinion, otherwise it will be that standard rather than the patient's need to know and respect for the patient's autonomy that will determine the information to be given (26). The view now seems to be adopted that the measure of disclosure is to be determined by the patient's need to know. Although this also imports judgment on the part of the health care professional, it emphasises the social value that is at stake, namely not so much meeting the standards of one's peers and colleagues or receiving their approbation for a job properly done, but dealing with the patient as a whole person and in a way that respects the patient's claim to ultimate control over his destiny, including his medical destiny.

A fourth problem that can be lightly touched upon and passed by is the misuse of consent for wrongful purposes. Cases have arisen where informed consent is given for a particular medical procedure but then misused either for another procedure or for improper motives. Many of these cases involve people who are not doctors, passing themselves off as medical practitioners, thereby securing a consent which is vitiated because given on an incorrect footing (27). Just the same, these cases do emphasise the need for continuing consent during a course of treatment and the need to ensure that the treatment being given is still that for which the consent was initially accorded.

A fifth area of difficulty relates to experiments for non-therapeutic purposes. This problem has already been mentioned in the case of children where it is at its most acute. There appears to be no doubt that a higher duty exists of frankness and informed consent where the health care professional is not treating or not solely treating the patient, but is engaging in a course of research. It is here that particularly careful explanation must be given to the patient so that informed consent can be secured. The rule is clearly stated in the Declaration of Helsinki (6). Critics of the rule have pointed out that too strict an observance of this criterion may mean important restrictions on research. Excessive caution, it is said, could cost lives (6). In some cases, involving the use of a placebo, experiments would be rendered worthless by complete frankness with the patient (28). Just the same, notions that any form of experimentation might be thought justified because a patient was going to die, are completely out of accord with our laws, our ethical practices and moral principles. Some authors have suggested the use of the test 'would I do this to Einstein or Picasso?' or even more cogently 'to one of my own family' (6). However, such a test does not appear to me to be very helpful. It is circular in the sense that if the standards of the practitioner, carried away with the enthusiasm of research, are lowered, he might indeed carry out the experiments without the knowledge of his family. This may simply underline his lack of respect for the autonomy of those with whom he is experimenting. Where non-therapeutic procedures are involved, the duty of securing informed consent is high. Of course, many of such cases do not come to the notice of the law or the courts. But were they to do so, I am sure the law would, 
resorting to general principle, stress the importance of a frank statement to the patient that he is part of an experimental regime. Most patients, with confidence in their medical professional, will agree. But they should have the right to disagree or to seek treatment elsewhere.

\section{Conclusions}

What conclusions are to be drawn from this discussion? One could wash one's hands of the issue by simply saying that the topic is already overburdened with discussion, that concepts and the reality of informed consent do not coincide and that we must simply put our faith in the members of the medical profession and in the procedures for selecting, testing and training them as well as in peer pressure within the profession against improper conduct.

I doubt if this will be enough, certainly for the better educated and better informed patient of the 21 st century. The days of paternalistic medicine are numbered. The days of unquestioning trust of the patient also appear numbered. The days of complete and general consent to anything a doctor cared to do appear numbered. Nowadays doctors, out of respect for themselves and for their patients, (to say nothing for deference to the law) must increasingly face the obligation of securing informed consent from the patient for the kind of therapeutic treatment proposed.

I have indicated my lack of confidence in the socalled golden rule: would I do this procedure to my own child, to a famous person, or to my own family? Although such a reference to the golden rule may be helpful as a rule of thumb, it is not very specific because different people will apply it in different ways according to their personal moral standards and enthusiasms.

There seems to be no alternative to a clear understanding of the rationale that is behind the principle of informed consent. It is this ethical principle which underpins the law's insistence on it. An understanding of this rationale will lead to a perception of the need for oral discussion and where necessary detailed consultation with the patient, to explain the treatment, the risks, the alternatives, the dangers and to give any additional information that is appropriate. The need for oral discussion in addition to the frequently used consent forms is emphasised by many writers (29) who have examined the serious lack of recall of people rushed through the procedure of consent forms at the hospital door or surgery office. From the medical professional's own point of view the desirability of making notes concerning the consultation and the detail of information given has also been stressed, not simply out of self-defence but as a programme to discipline the professional in the procedures of providing the key information to the patient (30). As treatment progresses and as further consent may be required, progress notes should also be kept.

Forms are, I suppose, indispensable in the nature of modern medical practice. It should be said that they are not imperative, for a nod or a gesture could in some cases imply an appropriate consent (31). However, especially if treatment is to be of a serious or radical kind, some form of written consent should be obtained both out of self-protection and as a symbol of the importance of securing consent (19). Obviously, securing signatures on forms is not enough as the experimental evidence referred to above will show. People simply do not absorb the information and many, in current practice, are not really given an opportunity to do so. A Roneo-d form is placed in front of them, their signature is required. They are often not in a very good position to question, negotiate or bargain. Often, the forms are in a legalistic language which would fail a rudimentary readability test (28). Suggestions have been made that readability tests should be used upon at least major hospital forms. We should not scoff at this idea. The Australian Law Reform Commission is examining the suggestion in respect of insurance contracts which represent another area where ordinary folk come into contact with detailed documentation that can profoundly affect their welfare but which may be expressed in language which is obscure or requires a comprehension or education far beyond the average.

In America there is an increasing tendency for medical professionals to use tape-recordings of conversations about critical medical consent decisions (9). I would certainly not consider this to be necessary in Britain or Australia. Our cost rules especially have prevented the development here of the flourishing industry of medical malpractice that exists in the United States. Defensive tape-recording would appear to be an unnecessary deviation from a basically accepted relationship of dependence and trust, at least at this stage. However, we should not put out of our minds the possibility of the use, in areas of specialty, of a tape-recording or even video cassette which a patient can take home and play and which explains in accurate detail the basic issues to which the patient (and his family) must address themselves. If the research is right and people simply do not understand the forms and explanations that are now being used, the goals of informed consent will only be realised if we pay more attention to communication with patients. The medical and legal professions should give more thought to the way they can better do this, using the modern instruments of electronic communication. I realise that cases differ and that necessarily information for particular patients will differ too. But the notion at least in serious, complex and risky procedures of providing patients with oral information which they can take away and consider at leisure, and give time and thought to, is a desirable goal that should be given careful thought.

Various authors suggest other means of tackling the problem of informed consent. It is said that we can do more in the medical schools to promote an understanding of the ethical and legal obligations that are involved. It is said that we can introduce peer pressure, 
particularly in experimental and non-therapeutic work. It is said that editors of medical journals can keep control over the publication of material which plainly manifests a lack of respect for the autonomy of patients who are the subject of experimentation (21).

None of these suggestions, whether the golden rule, revision of forms, use of oral communications, better medical training or peer pressure represent a complete answer to the dilemmas of informed consent. This is because there is no complete answer. The most, as it seems to me, that ethical rules and the law can do is to emphasise, lest it ever be forgotten, the integrity and autonomy of the patient. Most medical professionals do not forget. Most are faithful to the trust put in them by patients dependent because of need. An American writer, both a Doctor of Medicine and a Doctor of Laws, put it thus:

The physician need have no fear of a legitimate malpractice suit if he deals with ... patients as he himself would wish to be dealt with . . . that is, by adhering to the state of the art in his standard of care, by never losing patience or giving up hope, by never telling a patient his condition is hopeless, and by always involving the patient in his own therapy.

In this way, the physician adheres to the principal objective of the medical profession, which is to render service to humanity with full respect for the dignity of man, meriting the confidence of patients entrusted to his care, rendering to each a full measure of service and devotion, and protecting his patients from worthless and possibly harmful remedies for which the charismatic but unscrupulous make miraculous claims. The fact that the patient gave an informed consent usually will not prevent him from suing; a warm relationship with a competent and caring physician usually will (2).

\section{References and notes}

(1) Herbert V. Informed consent - a legal evaluation. Cancer 1980; 46: No 4: 1042-1043.

(2) See reference (1) 1043.
(3) Thomson J H. Informed consent to medical treatment in the United States. Medical journal of Australia 1979; 2: $412-415$.

(4) Williams v Menehan 1963; 379 P2d 292, Kan. See also reference (1) 1043.

(5) Helsinki Declaration cited Campbell A G M. Infants, children and informed consent. British medical journal 1974; 3: 334.

(6) Anonymous. When is consent? [editorial]. Lancet 1967; 2: 813 .

(7) Mr Justice Frankfurter in Tiller v Atlantic Coastline Railway. 1943; 318 US 54, 68.

(8) Slater v Baker and Stapleton, 94 ER 860.

(9) See reference (1) 1042.

(10) See discussion in Law Reform Commission of Canada Consent to medical care, Study Paper (Somerville M A) $1979 ; 3$.

(11) Gallon v Meyerson 522 P2d 852.

(12) See reference (3) 415.

(13) Skegg P D G. 'Informed consent' to medical procedures. Medicine, science and law 1975; 15, No 2: 124-128.

(14) See reference (10) 25-26.

(15) See reference (3) 412.

(16) See reference (10) 112.

(17) See reference (3) 412, and reference (13) 129.

(18) Mr Justice McNair in Bolam v Friern Hospital. 1957; 2 All ER 118. Discussed in British medical journal 1980; 280: 574.

(19) See reference (10) 113.

(20) See reference (10) $99 ; 113-114$.

(21) See reference (5) 337.

(22) Australian Law Reform Commission. Privacy and personal information ALRC DP 14: 59-64.

(23) See reference (13) 130.

(24) Cassileth V R, others. Informed consent - why are its goals imperfectly realised? New England journal of medicine 1980; 302: 896.

(25) See reference (13) 128.

(26) See reference (3) 414.

(27) See reference (13) 125.

(28) See reference (5) 335.

(29) Vaccarino J M. Consent, informed consent and the consent form [editorial]. New England journal of medicine 1978; 298: 8: 455. See also reference (24).

(30) See reference (1) 1043, and reference (29), Vaccarino J $M$.

(31) See reference (13) 127. 